\title{
Rapid communication Fundamental study of a one-step ambient temperature ferrite process for treatment of acid mine drainage waters
}

\author{
BE Morgan, RE Loewenthal and O Lahav* \\ Department of Civil Engineering, University of Cape Town, Rondebosch 7700, South Africa
}

\begin{abstract}
A novel approach towards the removal of iron and heavy metals from South African acid mine drainage (AMD) waters is presented. The approach involves the controlled oxidation of ferrous-containing AMD water at ambient temperatures in the presence of magnetite seed. The resulting oxidation product is the ferrite $\left(\mathrm{M}^{3+}{ }_{2} \mathrm{M}_{2}{ }^{2+} \mathrm{O}_{4}\right)$ magnetite $\left(\mathrm{Fe}_{3} \mathrm{O}_{4}\right)$, which has the capacity for nonferrous metal removal, and which forms a stable sludge that is easily separated from the effluent. Sludge characterisation studies (XRD, SEM and dissolution tests) show that oxidation of ferrous solutions under controlled $\mathrm{pH}$ and oxidation conditions ( $\mathrm{pH} 10.5$, air flow rate $=0.05 \mathrm{l} / \mathrm{min}$ ) in the presence of magnetite seed (initial seed : ferrous ratio $=7: 1$ ) yields almost pure magnetite at ambient temperature. It was found that magnetite seed channels the end products of the AMD oxidation reaction towards magnetite. Under identical conditions, but in the absence of magnetite seed, a poorly characterised mixture of largely amorphous iron oxides are formed with magnetite comprising not more than $17 \%$ of the total iron. The kinetics of the reaction under the investigated conditions were found to be very favourable, with magnetite forming at a rate of $12.8 \mathrm{mg} \mathrm{Fe} / / / \mathrm{min}$. The total iron concentration in the effluent was always less than $1 \mathrm{mg} / /$ representing an iron removal efficiency of $99.9 \%$. The precipitant settled well (SVI $8 \mathrm{~m} / \mathrm{g}$ ) and showed substantial stability at $\mathrm{pH} 3$ (dissolution of $1.1 \%$ after $120 \mathrm{~h}$ ). An outline for a one-step ambient temperature ferrite process is presented.
\end{abstract}

\section{Introduction}

Acid mine drainage (AMD) impacts negatively on freshwater resources in the mining areas of South Africa and many other parts of the world. AMD waters are characterised by low $\mathrm{pH}$, very high iron concentrations, significantly high concentrations of nonferrous (mainly heavy) metals, and very high salinity, principally in the form of sulphate. The chemical makeup of AMD is directly explicable in terms of the biogeochemical process whereby AMD arises: put most simply, mining activities allow atmospheric oxygen and water to contact and, together with the action of aerobic bacteria, oxidise iron pyrite $\left(\mathrm{FeS}_{2}\right)$ in the rock. This releases sulphate and iron into underground water making the latter strongly acidic, causing leaching of non-ferrous metals from the rock (Kleinmann et al., 1981). A comprehensive solution to AMD pollution requires both metal and sulphate removal. The latter can be effected by either biological or membrane-based methods. Irrespective of the method of sulphate removal, iron and nonferrous metals must be removed beforehand.

Current strategies for metal removal from AMD have several shortcomings (Loewenthal et al., in press; Bosman, 1983). The high density sludge (HDS) process, deployed on several South African mines, utilises lime for $\mathrm{pH}$ adjustment and oxygen to vigorously oxidise ferrous iron. A recycle loop is used to densify the ferrihydrite precipitant which is otherwise difficult to separate from the liquid phase. Minimal non-ferrous metals are removed and high oxygen concentrations are required. These limitations, coupled with the magnitude of the AMD problem (some mining basins pump up to $60 \mathrm{M} \ell$ of water per day), underscore the need for improved cost-effective treatment methods.

\footnotetext{
* To whom all correspondence should be addressed.

唺(021) 650-2618; fax (021)689-7471; e-mail: olahav@eng.uct.ac.za Received 28 February 2001
}

Magnetite is a partially oxidised iron oxide with the formula $\mathrm{Fe}_{3} \mathrm{O}_{4}$ (i.e. $\mathrm{Fe}^{3+}{ }_{2} \mathrm{Fe}^{2+} \mathrm{O}_{4}$ ). Thus, it conforms to the general formula $\mathrm{M} 1{ }^{3+}{ }_{2}{ }^{2+} \mathrm{O}_{4}$ for ferrites, where $\mathrm{M} 1$ and $\mathrm{M} 2$ stand for any of a number of possible metal elements. Magnetite is a ferrite in which the metal component is made up purely of iron. If a solution dominated by soluble iron but containing smaller concentrations of other divalent and trivalent metal species (such as are found in AMD) is transformed into ferrite, then the resulting precipitant will be dominated by magnetite but some of the iron atoms will be replaced by non-ferrous cations, making for "substituted magnetite" or "mixed-species" ferrites.

Barrado et al. (1998) proposed the following stoichiometric reactions for ferrite formation from ferrous at $\mathrm{pH}>10.5$ :

In the absence of heavy metals and with a slow oxidation rate

$$
3 \mathrm{Fe}(\mathrm{OH})_{2}+3 \mathrm{SO}_{4}^{2-}+6 \mathrm{Na}^{+}+0.5 \mathrm{O}_{2}{ }^{\circledR} \mathrm{Fe}_{3} \mathrm{O}_{4}+3 \mathrm{Na}_{2} \mathrm{SO}_{4}+3 \mathrm{H}_{2} \mathrm{O}
$$

Equation (1) shows that alkalinity is neither produced nor consumed during the formation of magnetite from ferrous hydroxide, and that $10.47 \mathrm{mg} / \ell$ of magnetite (as Fe) are formed for every $1 \mathrm{mg} / \ell$ of oxygen consumed.

In the presence of heavy metals and with a slow oxidation rate

$$
\begin{aligned}
& \mathrm{xMe}^{+\mathrm{n}}+3 \mathrm{Fe}(\mathrm{OH})_{2}+3 \mathrm{SO}_{4}^{2-}+6 \mathrm{Na}^{+}+0.5 \mathrm{O}_{2}{ }^{\circledR} \mathrm{Me}_{\mathrm{x}} \mathrm{Fe}_{3-\mathrm{x}} \mathrm{O}_{4} \\
& +3 \mathrm{Na}_{2} \mathrm{SO}_{4}+3 \mathrm{H}_{2} \mathrm{O}+\mathrm{xFe}^{+\mathrm{n}}
\end{aligned}
$$

$\mathrm{Fe}^{+\mathrm{n}}$ represents the total concentration of iron which is replaced by metal cations in the ferrite structure. This displaced iron will appear as ferrous or ferric depending on the valence of the displacing cation. These ferrous and ferric ions will react to form magnetite.

However, it is to be noted that with excess oxidising agent, goethite is formed instead of magnetite:

$$
2 \mathrm{Fe}^{2+}+0.5 \mathrm{O}_{2}+4 \mathrm{OH}^{-}{ }^{\circledR} 2 \mathrm{a}-\mathrm{FeOOH}+\mathrm{H}_{2} \mathrm{O}
$$


The formation of relatively pure precipitates of magnetite from ferrous solutions was until recently only thought to be possible at temperatures greater than $90^{\circ} \mathrm{C}$ (Kiyama, 1974; Cornell and Schwertmann, 1996). Nevertheless, the capacity of magnetite to absorb by substitution non-ferrous metals, plus the advantageous settling properties of magnetite, have resulted in the exploitation of magnetite formation as a means to remove metal ions from waste streams. The "ferrite process" refers to a high temperature process $\left(65^{\circ} \mathrm{C}\right)$ developed in Japan for the treatment of laboratory wastes containing heavy metals (Katsura et al., 1977; Tamaura et al., 1991a;b). However during the last decade, several developments in the field of ambient temperature ferrite chemistry have occurred which appear to be opening the way to treating large volumes of water such as AMD.

Tamaura et al. (1991b) first applied the ferrite process at ambient temperature as a two-step process in which a ferrous AMD stream is split into two. One stream is oxidised to ferric and the streams are then recombined at an elevated $\mathrm{pH}$ whereupon magnetite is formed. Wang et al. (1996) found the optimum ferric:ferrous ratio for ambient temperature magnetite formation to resemble the stoichiometric ratio (i.e. 2:1) of these ions in magnetite. These authors also investigated the effects of both non-ferrous metals (as found in a Canadian AMD) and calcium on ambient temperature ferrite formation. Finding that calcium, but not non-ferrous metals, interfered decisively with ferrite formation, this same group investigated the effects of magnetite seed. It was found that magnetite seed restored the capacity for ferrite formation at ambient temperature in the presence of calcium; and a "seeded ambient temperature ferrite process" for AMD was presented. This scheme requires stoichiometric adjustment by supplementary ferrous salt addition (McKinnon et al., 2000). Earlier, Perez et al. (1998) found that recycling of magnetic precipitates formed during (i.e a onestep process) the oxidation of ferrous sulphate solutions in the presence of calcium had a positive effect on ferrite formation at ambient temperature.

The potential for mixed-species ferrite formation at ambient temperature in the presence of calcium using seed thus appears possible as either a one-step, in-line oxidation procedure or by a two-step split-stream stoichiometric combination procedure. At present there is no indication that one of these two methods is superior. Indeed the sparse literature on ambient temperature ferrite formation reflects the infancy of this field and, in particular, there is little published information with respect to key process parameters such as kinetics, heavy metal substitution, effect of calcium, settling behaviour, and sludge stability. Preliminary studies conducted by the writers confirmed the feasibility of the one-step approach. On the basis of this, plus the cost advantages of a one-step process, a systematic investigation into the fundamentals of a onestep ambient temperature ferrite process for treatment of AMD was initiated.

The results reported in this communication illustrate how the use of seed facilitates the formation of magnetite by the aerial oxidation of AMD at ambient temperature. For reasons of simplicity, the current investigation is confined to magnetite formation using seed at ambient temperature via the oxidation of pure ferrous sulphate solutions and does not address the issues of non-ferrous metals or calcium. The emphasis of this work is to properly understand and quantify the chemistry underlying ferrite formation as applied to AMD in order to design and implement a treatment process. The role of these other elements will be systematically introduced and investigated in due course. Other aspects relevant to a magnetite seed-based process, such as kinetics of oxidation, sludge settlement, sludge impurities and sludge stability are also discussed briefly. Comprehensive optimisation of major operational parameters is currently under investigation and will be reported in a future publication.

\section{Materials and methods}

\section{Reagents}

The following analytical grade reagents (Sigma-Aldrich) were used as received: $\mathrm{FeSO}_{4} .7 \mathrm{H}_{2} \mathrm{O}, \mathrm{Na}_{2} \mathrm{SO}_{4}, \mathrm{NaOH}, \mathrm{KOH}$, hydrazine sulphate, $\mathrm{KNO}_{3}, \mathrm{NaHCO}_{3}, 32 \% \mathrm{HCl}, 1,10$-phenanthroline monohydrate, glacial acetic acid, $\mathrm{NH}_{4} \mathrm{C}_{2} \mathrm{H}_{3} \mathrm{O}_{2}$.

\section{Instrumentation and methods for measurements}

$\mathrm{pH}$ was measured with a Metrohm $\mathrm{pH}$ probe-temperature transducer coupled to a Metrohm 744 meter. Dissolved oxygen was measured with a YSI 5739 DO probe coupled to a Hitec Micro Systems (Cape Town, SA) meter. Bottled air and nitrogen, fed through rigid gas tubing, were passed sequentially via an adjustable pressure regulator and a rotameter flowmeter to the reactor. At the reactor, soft flexible tubing conveyed the gases to a stone bubbler fixed to the middle of the reactor floor. Ferrous iron was measured by the phenanthroline method (Standard Methods, 1998). Total iron was determined by atomic absorption using a Varian SpectrAA 30 spectrometer. During a cycle, total iron was measured using a bench-top Spectroquant (Merck) system. Magnetite which served as the initial seed to start up each experiment was made according to the method suggested by Regazzoni et al. (1981).

All experiments were performed in a clear perspex reactor with internal dimensions of $18.75 \times 11.5 \times 11.5 \mathrm{~cm}^{3}$ (height $\mathrm{x}$ width $\mathrm{x}$ width) capable of holding $2.62 \ell$. The reactor was fitted with a lid which has a large centrally-positioned circular port and four smaller ports positioned in each corner. The central port accommodated the shaft of the mixing paddle $\left(7.5 \times 2.5 \mathrm{~cm}^{2}\right.$, width $\mathrm{x}$ height) which rotated through a bearing fixed above the reactor. The top of the paddle was located $7 \mathrm{~cm}$ above the reactor floor and was centrally positioned directly above the bubbler through which air $/ \mathrm{N}_{2}$ are released. The large central port was also used to add reagents to and take samples from the reactor and also accommodated the DO probe.

\section{Experimental procedure}

Each experiment consists of a sequence of repeated batch cycles. The procedure for each cycle was identical: the premix consists of distilled water containing approximately $8.4 \mathrm{~g} / \ell$ of seed which was stirred continuously at $187 \mathrm{r} / \mathrm{min}$. Prior to the addition of ferrous sulphate, $\mathrm{N}_{2}$ gas was liberally bubbled for $10 \mathrm{~min}$ from the bottom of the reactor in order to deoxygenate the premix which was maintained at a $\mathrm{pH}$ below 4 at this stage. $0.0215 \mathrm{M} / \ell$ of $\mathrm{FeSO}_{4} \cdot 7 \mathrm{H}_{2} 0$ (giving an initial ferrous concentration of $1200 \mathrm{mg} / \ell$ ) was then added to the reactor. This established a seed: ferrous ( $\mathrm{Fe}: \mathrm{Fe})$ starting ratio of $7: 1 . \mathrm{NaSO}_{4}$ was then added to establish a $\mathrm{SO}_{4}{ }^{2-}: \mathrm{Fe}$ ratio of 2:1 characteristic of AMD. The $\mathrm{pH}$ was then raised to 10.5 by the addition of $5 \mathrm{MNaOH}$ and aeration commenced at $0.05 \mathrm{l} / \mathrm{min}$ (air pressure upstream of the flowmeter $=100 \mathrm{KPa}$ ). $1 \mathrm{~m} \ell$ samples were then taken at regular intervals until the end of the cycle. During the course of the cycle the $\mathrm{pH}$ was maintained at 10.5 by the addition of small volumes of $1 \mathrm{M} \mathrm{NaOH}$. The amount and time of addition of each dose of $\mathrm{NaOH}$ was recorded. Changes in the DO value were also recorded. Prior to the commencement of the next cycle a calculated amount of seed was removed from the reactor in 
order to restore the seed concentration to $8.4 \mathrm{~g} / \ell$. The supernatant was also removed and replaced twice with distilled water between cycles in order to prevent salinity accumulating in the reactor.

Experiments without seed: These were conducted in an identical fashion to that described above, the only differences being that no seed was present in the premix and no recycling was performed.

Sludge settling tests: At the end of the cycle, mixing was stopped and the suspended solids were allowed to settle. After 30 min of settling time the volume of the settled solids was measured. Settlement results are depicted as sludge volume index (SVI) (Standard Methods, 1998).

Supernatant measurements: $2 \mathrm{~h}$ after the end of the cycle a $5 \mathrm{~m} \ell$ sample of raw supernatant was taken, and without further processing, assayed for total iron concentration.

Sampling procedure during cycle: The $1 \mathrm{~m} \ell$ samples taken during each cycle were taken from approximately halfway down the depth of the reactor. Each $1 \mathrm{~m} \ell$ sample of reactor contents was immediately diluted to $100 \mathrm{~m} \ell$ in a volumetric flask with $0.01 \mathrm{M}$ $\mathrm{HCl}(\mathrm{pH} 2)$. The sample was mixed by shaking and was allowed to stand for 5 minutes. The sample was then vacuum filtered through a 0.45 micron membrane filter and $50 \mathrm{~m} \ell$ of the filtrate were set aside for later analysis of total iron and ferrous iron concentrations. The remaining filtrate was used to monitor total iron concentration during the course of a cycle. The membrane filter used to process the final sample for any cycle was retained and allowed to dry at room temperature overnight. The residue of seed and precipitated solids on the filter was then subjected to XRD and SEM analysis.

\section{Characterisation of precipitant}

Characterisation of the precipitant was performed using two qualitative (XRD and SEM) and one quantitative method (ferrous to total iron ratio):

Scanning electron microscopy (SEM): The precipitated material deposited on the membrane filter of the final sample of each cycle was examined by SEM.

X-ray diffraction: A section of the same filter from each cycle used for SEM was subjected to XRD analysis using a Phillips PW3710 XR diffractometer with a normal four copper tube.

$\mathbf{F e}^{2+} / \mathbf{F e}_{\mathrm{T}}$ ratio in sludge: Two $20 \mathrm{~m} \ell$ samples taken from high and middle zones of the mixed reactor were dissolved in $30 \mathrm{~m} \ell$ of $32 \%$ $\mathrm{HCl}$. Complete dissolution takes about $15 \mathrm{~min}$, whereafter the $\mathrm{pH}$ of the solutions was immediately raised to 1.3 by addition of a well deoxygenated $5 \mathrm{M} \mathrm{NaHCO}_{3}$ solution. The precise volume was measured before the sample was further diluted with distilled water to a concentration suitable for total iron and ferrous measurements.
Figure 1

$R D$ tracing of the precipitant from the experiment with seed ( $\left.8^{\text {th }} \mathrm{cycle}\right)$

\section{Results and discussion}

Reaction pathways followed and intermediate and end-products generated during the oxidation of ferrous solutions vary according to conditions of $\mathrm{pH}$, temperature, concentration of reactants, presence and type of anions, mixing conditions, etc. in ways which are complex and poorly understood (Sugimoto and Matijevic, 1980; Blesa and Matijevic, 1989; Cornell and Schwertmann, 1996). By and large, conditions inducing magnetite formation from ferrous solutions are slow oxidation, strongly alkaline $\mathrm{pH}$, high ferrous concentrations and high temperature (Cornell and Schwertmann, 1996).

In this work, pure ferrous solutions ( $1200 \mathrm{mg} / \mathrm{l}$ as $\mathrm{Fe})$ were oxidised at low air flow rate $(0.05 \ell$ air $/ \mathrm{min}), \mathrm{pH} 10.5$, high sulphate concentration, rapid mixing conditions and ambient temperature. The experiments were carried out in batch fashion in the presence and absence of magnetite seed. Experiments without seed comprised a single batch test, whereas those with seed consisted of a sequence of repeated identical batch tests with recycling of the seed from one cycle to the next. With respect to the latter, the results presented below were taken from the eighth cycle of such an experiment by which time the chemical composition of the seed had reached steady state.

\section{Formation of magnetite at ambient temperature with in-line aerial oxidation}

Experiments conducted with and without magnetite seed showed clearly that seed strongly channels the reaction towards magnetite formation. Experiments without seed produced a yellow-orange precipitant consisting of a mixture of iron species. This precipitant displayed poor settling characteristics and a relatively weak response to a hand magnet. SEM examination revealed a partially crystallised, partially amorphous structure with no apparent magnetite particles (Fig. 2a). The XRD pattern consisted of a few clear peaks (which did not match magnetite) and high background noise. A searchmatch analysis suggested that gypsum and $\mathrm{Fe}_{6}(\mathrm{OH})_{12} \mathrm{CO}_{3}$ were present (data not shown). Ferrous to total iron ratio in this precipitant was $5.7 \%$, which is indicative of a maximum presence of magnetite 

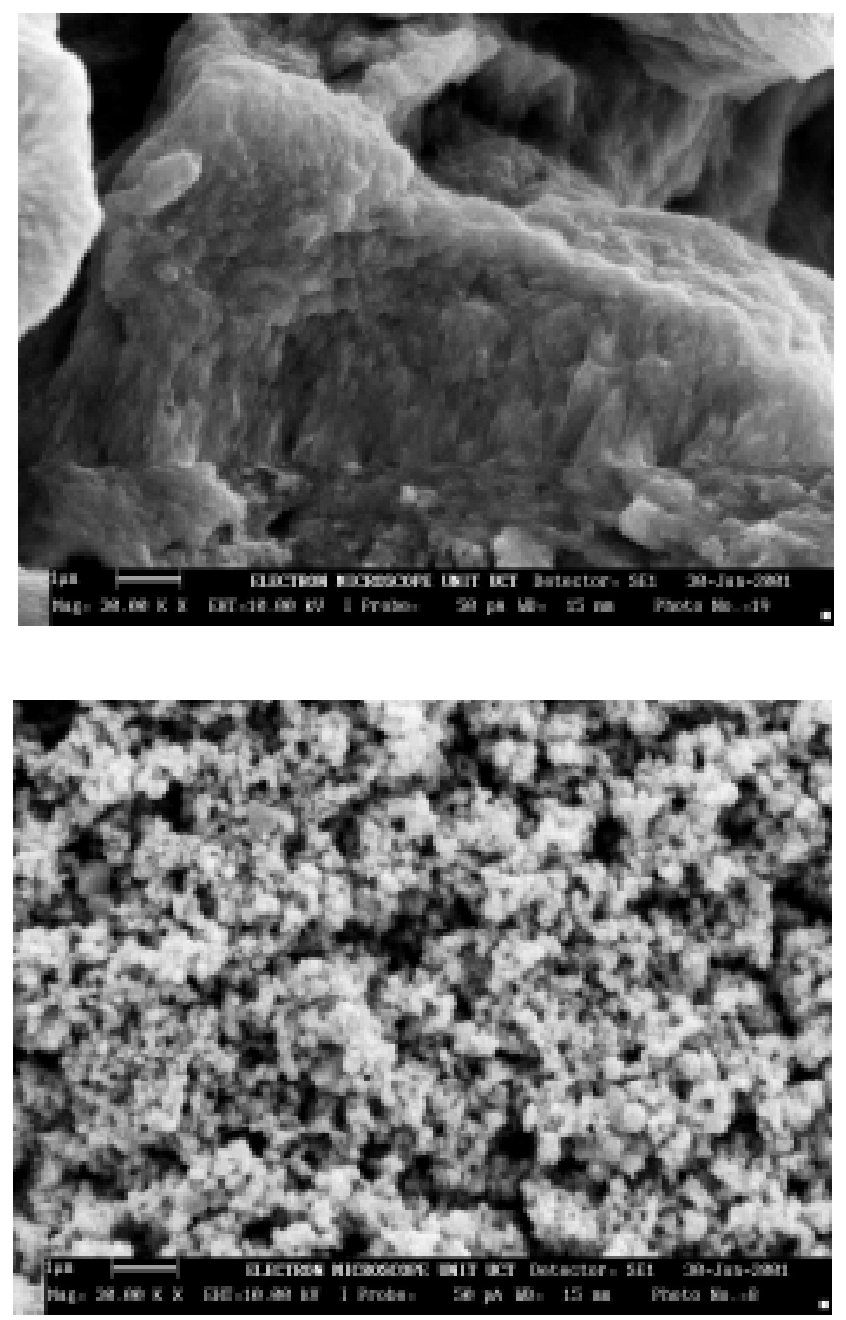

Figure 2

Scanning electron micrographs of precipitants:

a) Experiment without seed

b) Experiment with seed

(Magnification $=x 30000)$

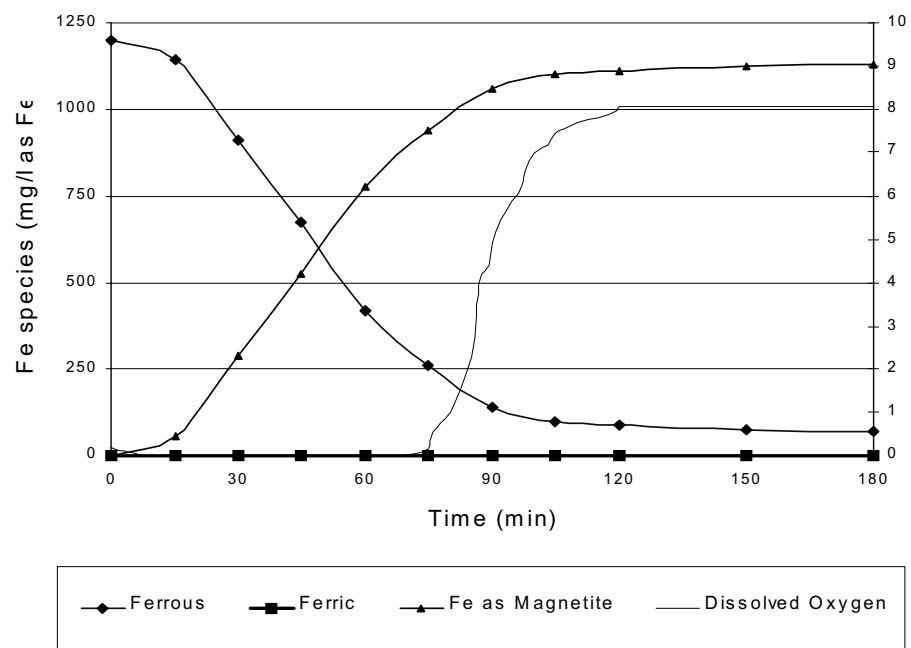

of around $17 \%$ of the total iron. Further characterisation of the species present in this precipitant was not pursued.

Experiments with seed produced a precipitant that was charcoalblack in colour, settled very well (SVI $8 \mathrm{ml} / \mathrm{g}$ ), and reacted strongly to a hand magnet. XRD analysis indicated the presence of magnetite with no other peaks occurring (Fig. 1). SEM shows small cuboid particles consistent with the appearance and size ( $\sim 0.1$ micron) of magnetite (Fig. 2b). Ferrous to total iron ratio in this precipitant was $\sim 30 \%$. The stoichiometric ratio being $33.3 \%$, this value is well within the range reported for magnetite in the literature (Kiyama, 1974; Cornell and Schwertmann, 1996).

Magnetite formation occurred at a rate of $12.8 \mathrm{mg} \mathrm{Fe} / \mathrm{l} \cdot \mathrm{min}$ during the linear phase of the reaction (Fig. 3). During this phase the DO concentration was zero and the oxygen utilisation efficiency was around $22 \%$. The amount of base $(\mathrm{NaOH} 1 \mathrm{M})$ added to the reactor during an entire cycle in order to maintain the $\mathrm{pH}$ at 10.5 was $4.5 \mathrm{mmoles} / \ell\left(225 \mathrm{mg} / \ell\right.$ as $\left.\mathrm{CaCO}_{3}\right)$. This alkalinity requirement was attributed to a combination of $\mathrm{CO}_{2}$ absorption and precipitation of minute concentrations of iron hydroxides. After settling of the precipitant, the concentration of iron in the supernatant was always below $1 \mathrm{mg} / \ell$.

Tests of precipitant stability at $\mathrm{pH} 3(0.001 \mathrm{M} \mathrm{HCl}$ solution) revealed that only $1.1 \%$ (mass/mass) of the precipitant dissolved after $120 \mathrm{~h}$. These leaching results are in keeping with those reported by Wang et al. (1996).

\section{Kinetics}

Figure 3 shows results from a typical batch test with seed following the sampling procedure described in materials and methods. Results were taken from the eighth cycle to ensure that the solids in the reactor were predominantly endogenous. Results of the two previous cycles were identical to the results shown and discussed here, indicating that the system has reached steady state with respect to the precipitated solids. In this section the term 'ferrous (or ferric) intermediate' represents the fraction of the mixed sludge that is soluble as ferrous (or ferric) after $5 \mathrm{~min}$ at $\mathrm{pH} 2$.

Ferrous-intermediate, ferric-intermediate, and oxygen concentrations shown in Fig. 3 are measured values while magnetite values are calculated on the basis that magnetite is the sole endproduct stable at $\mathrm{pH} 2$ as supported by the XRD, SEM and dissolution results given above.

Figure 3 illustrates that the ferric-intermediate concentration remains at zero throughout the cycle. Since ferrihydrite is rapidly soluble at $\mathrm{pH} 2$ and ferrous iron is being oxidised, it indicates that ferric iron is being incorporated into magnetite. This situation contrasts with that observed at higher air flow rates where significant concentrations of ferric iron were measured (data not shown).

Figure 3 reveals that the pattern of disappearance of ferrous-intermediate (oxidation to ferric plus incorporation of ferrous into magnetite) occurs in two distinct phases. For the first 75 min oxidation is essentially linear at a rate of $\sim 12.8 \mathrm{mg} \mathrm{Fe} e^{2+} / \ell \cdot \mathrm{min}$. Throughout this initial phase the DO concentration was zero, indicating that the oxygen transfer was the rate-limiting step. After $75 \mathrm{~min}$ an abrupt steep increase in the DO concentration occurred at which

Figure 3

Changes in concentration of iron species and oxygen with time during a typical cycle with seed 


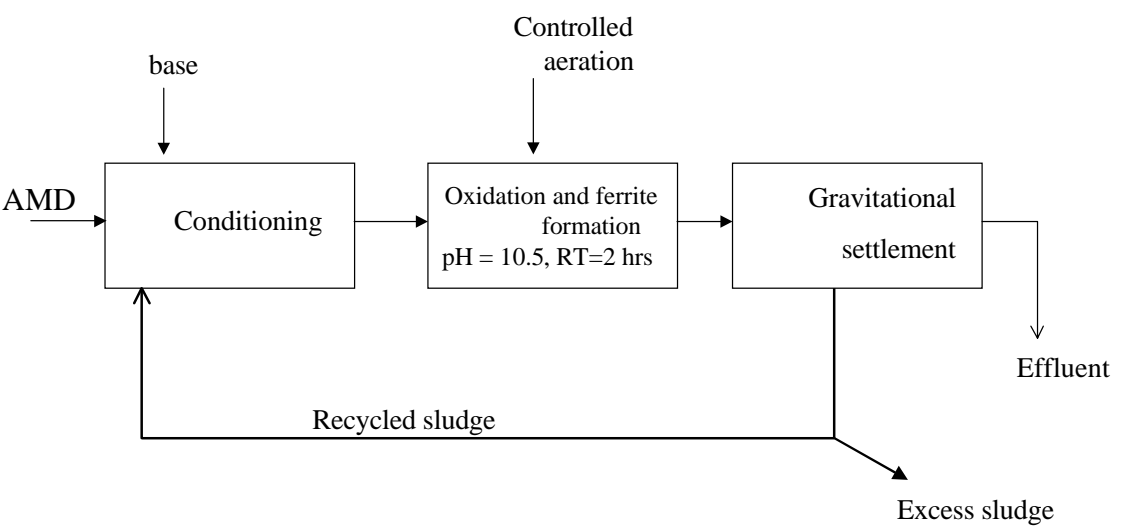

time the rate of ferrous-intermediate oxidation declined rapidly (DO concentration increased to $4 \mathrm{mg} / \ell$ at $90 \mathrm{~min}$ ) and the ferrousintermediate curve followed an asymptotic shape at a value of $\sim 75 \mathrm{mg} / \ell \mathrm{Fe}^{2+}$. Taken together, these results allow calculation of the magnetite formation curve $\left(\left[\right.\right.$ magnetite $\left._{t}\right]=$ [initial ferrous $]-$ ([ferrous-intermediate $\left.t_{t}\right]+\left[\right.$ ferric-intermediate $\left.\left._{t}\right]\right)$ ) which is, in this case, almost a mirror image of the ferrous curve.

Several authors have made mention of possible mechanisms of formation of magnetite in the presence of seed (Perez et al., 1998; McKinnon et al., 2000). Little is known of this reaction but phenomenologically it can be said that seed alters the reaction pathway, possibly involving a ferrous species-magnetite complex, which channels the reaction towards magnetite formation.

Referring to Fig. 3, at the end of the linear phase, the ferrousintermediate curve assumes an asymptotic shape. Consequently a residual amount of ferrous-intermediate was always recoverable, having not been incorporated into magnetite, or at least not irreversibly so. This observation can be explained in two possible ways:

- as a substrate associated phenomenon which can be attributed to either an "armouring effect" (i.e. some of the ferrousintermediate is sealed off from the solution by the formation of new magnetite around it), or some other type of substrate or substrate-seed associated kinetic limitation; or

- as final product dissolution related to the sampling procedure (dissolution at $\mathrm{pH}$ 2).

With respect to these possibilities, preliminary investigations included the following experiment: At the end of a typical cycle a new cycle was performed with only $400 \mathrm{mg} / \mathrm{l}$ (instead of the usual $1200 \mathrm{mg} / \mathrm{l}$ ) of ferrous reagent added to the reactor. The oxidation rate observed in this case resembled the rate observed in the initial linear phase of a typical cycle as depicted in Fig. 3, but more importantly, this rapid-kinetics linear phase ended at approximately the same ferrous intermediate concentration as before $(\sim 150 \mathrm{mg} / \mathrm{l})$. This result suggests against a simple "armouring effect" but a substrate-related effect, or a substrate-seed interaction which renders the ferrous-intermediate relatively resistant to oxidation may still prevail. On the other hand, simple (stoichiometric) final product dissolution can be excluded since no ferric was found in the residue. Nevertheless, the behaviour of magnetite at the low $\mathrm{pH}$ value at which samples were taken is complex, and selective release of ferrous iron has been described (Jolivet and Tronc, 1988). The observed residual ferrous may therefore be ascribed to either or both a substrate/substrate-seed related effect and final product dissolution.

Although the above questions are currently being investigated, it must be emphasised that from a total iron concentration of
$1200 \mathrm{mg} / \ell$ at the beginning of a cycle, the supernatant at the end of a cycle contained less than $1 \mathrm{mg} / \ell$ of iron (removal effciency of $99.9 \%$ ). The residual ferrous-intermediate concentration discussed above pertains to a fraction of the ferrous iron which did not transform into magnetite, but which nevertheless settled with the rest of the solids. This fraction constitutes less than $1 \%$ of the total sludge.

\section{Summary and conclusions}

- A novel approach towards the removal of iron and non-ferrous metals from typical South African AMD waters is presented. This approach involves the controlled oxidation of ferrouscontaining AMD water at ambient temperatures in the presence of magnetite seed. The resulting oxidation product is the ferrite $\left(\mathrm{M}^{3+}{ }_{2} \mathrm{M} 2{ }^{2+} \mathrm{O}_{4}\right)$ magnetite $\left(\mathrm{Fe}_{3} \mathrm{O}_{4}\right)$ which has the capacity for non-ferrous metal removal by cation substitution. This results in a single, stable and easy to remove ferrite sludge that may also serve as a magnetic product.

- Sludge characterisation studies (XRD, SEM and dissolution tests) show that oxidation of ferrous solutions under controlled $\mathrm{pH}$ and oxidation conditions $(\mathrm{pH} 10.5$, air flow rate $=0.05$ $\ell / \min$ ) in the presence of magnetite seed (initial seed:ferrous ratio $=7: 1$ ) yields almost pure magnetite at ambient temperature. Under identical conditions, but in the absence of magnetite seed, a poorly characterised mixture of largely amorphous iron oxides are formed with magnetite comprising not more than $17 \%$ of the total iron.

- From a process perspective, the kinetics of magnetite formation under the above conditions (rate $=12.8 \mathrm{mg}$ as Fe $/ \ell \cdot \mathrm{min}$ ) are very favourable. At this rate the hydraulic retention time required for the complete removal of a typical AMD iron concentration $(1200 \mathrm{mg} / \ell$ ) is less than $2 \mathrm{~h}$.

- Under the batch test conditions reported here, the kinetics of ferrous-intermediate removal changed from approximately zero order kinetics to markedly slower rates. This change occurred at a residual ferrous concentration of around 200 $\mathrm{mg} / \ell$ and became asymptotic in the vicinity of $75 \mathrm{mg} / \ell$. It remains to be determined whether this is an intrinsic phenomenon under batch conditions or an artefact of the method of measurement.

- The total iron concentration in the effluent was always less than $1 \mathrm{mg} / \ell$ in all the experiments with seed, representing an iron removal efficiency of $99.9 \%$. The precipitant settled well (SVI $8 \mathrm{~m} / \mathrm{g}$ ) and showed substantial stability at $\mathrm{pH} 3$ (dissolution of $1.1 \%$ after $120 \mathrm{~h}$ ).

- Optimisation of parameters affecting magnetite formation at ambient temperature ( $\mathrm{pH}$, air flow rate, seed to $\mathrm{Fe}^{2+}$ ratio, effect of $\mathrm{Ca}^{2+}$ and $\left.\mathrm{Mg}^{2+}\right)$ are currently being investigated. Kinetics of 
non-ferrous metal removal are also under investigation.

- The one-step ambient temperature ferrite process as envisaged at this stage is depicted in Fig. 4.

\section{Acknowledgement}

The authors wish to thank the Water Research Commission of South Africa who provided financial assistance for this research.

\section{References}

BARRADO E, PRIETO F, VEGA $M$ and FERNANDEZ-POLANCO F (1998) Optimization of the operational variables of a medium scale reactor for metal containing wastewater purification by ferrite formation. Water Res. 32 (10) 3055-2061.

BLESA MA and MATIJEVIC E (1989) Phase transformations of iron oxides, oxo-hydroxydes, and hydrous oxides in aqueous media. Advances in Colloid and Interface Sci. 29 173-221.

BOSMAN DJ (1983) Lime treatment of acid mine water and associated solid/liquid separation. Water Sci. Technol. 15 71-84.

CORNELL RM and SCHWERTMANN U (1996) The Iron Oxides: Structure, Properties, Reactions, Occurrence and Uses. VCH, Germany.

JOLIVET J and TRONC E (1988) Interfacial electron transfer in colloidal spinel iron oxide. Conversion of $\mathrm{Fe}_{3} \mathrm{O}_{4}-{ }_{-} \mathrm{Fe}_{2} \mathrm{O}_{3}$ in aqueous medium. J. of Colloid and Interface Sci. 125 (2) 688-700.

KATSURA T, TAMAURA Y and TERADA H (1977) Treatment of the laboratory wastewaters by the magnetic separation process. Ind. Water 233 16-21.

KIYAMA M (1974) Conditions for the formation of $\mathrm{Fe}_{3} \mathrm{O}_{4}$ by the air oxydation of $\mathrm{Fe}(\mathrm{OH})_{2}$, suspensions. Bull. of the Chem. Soc. of Japan 47 (7) 1646-1650.
KLEINMANN RLP, CRERAR DA and PACELLI RR (1981) Biogeochemistry of acid mine drainage and a method to control acid formation. Mining Eng. 300-305.

LOEWENTHAL RE, MORGAN BE, and LAHAV O (in press) Iron and heavy metals in acid mine drainage waters - Equilibrium and treatment considerations. Accepted for publication in Water, Sewage and Effluent.

McKINNON W, CHOUNG JW, XU Z and FINCH JA (2000) Magnetic seed in ambient temperature ferrite process applied to acid mine drainage treatment. Environ. Sci. Technol. 34 2676-2581.

PEREZ OP, UMETSU Y and SASAKI H (1998) Precipitation and densification of magnetic iron compounds from aqueous solutions at room temperature. Hydrometallurgy 50 223-242.

REGAZZONI AE, URRUTIA GA, BLESA MA and MAROTO AJG (1981) Some observations on the composition and morphology of synthetic magnetites obtained by different routes. Inorg. and Nuclear Chem. 43 1489-93.

STANDARD METHODS (1998) Standard Methods for the Examination of Water and Wastewater $\left(20^{\text {th }}\right.$ edn. $)$ APHA.

SUGIMOTO T and MATIJEVIC E (1980) Formation of uniform spherical magnetite particles by crystallization from ferrous hydroxide gels. J. Colloid and Interface Sci. 74 (1) 227-243.

TAMAURA Y, TU PQ, ROJARAYANONT S, and ABE H (1991a) Stabilization of hazardous materials into ferrites. Water Sci. Technol. 23 399-404.

TAMAURA Y, KATSURA T, ROJARAYANONT S and ABE H (1991b) Ferrite process: Heavy metal ion treatment system. Water Sci. Technol. 23 1893-1909.

WANG W, XU Z and FINCH (1996) Fundamental study of an ambient temperature ferrite process in the treatment of acid mine drainage. Environ. Sci. Technol. 30 2604-2608. 